\title{
YABANCI RESSAMLARIN (15. YÜZYIL) TABLOLARINDA GÖRÜLEN TÜRK HALILARINDA RENKLER
}

\section{COLORS IN TURKISH CARPETS VIEWED ON THE PAINTINGS OF FOREIGN PAINTERS (15TH CENTURY)}

Ahmet AYTAÇ*

\begin{abstract}
$\ddot{O} z$
Yabancıların Türk halılarına olan ilgisi yüzyıllardır bilinmektedir. Özellikle XV. yüzyıldan sonra Avrupalı ressamlar tablolarında Türk halısı tasvirlemişlerdir.

Tablolardaki renkler ile tasvirlenen halının renkleri arasında bir bağ olduğu düşünülmektedir. $X V$. ve XVI. yüzyılın başlarında resim yapmış Rönesans ressamlarının bir kısmının bazı tablolarında Türk halıları vardır. Bu halıların desen analizi ve halıdaki renklerle tablodaki diğger renkler arasındaki bă̆lantı bu araştırma ile tespit edilmeye çalışılmıştır.
\end{abstract}

\section{Anahtar Kelimeler}

Hall, renk, ressam, resim.

\section{Abstract}

The interest of foreigners to the Turkish state has been known for centuries. Especially XV. After the century, European painters have depicted Turkish carpets on their paintings.

It is thought that there is a connection between the colors in the tables and the colors of the depicted figure. XV. and XVI. Some paintings of Renaissance painters painting at the beginning of the century have Turkish paintings. The pattern analysis of these carpets and the connection between the colors in the carpet and the other colors in the table have been tried to be determined with this research.

\section{Keywords}

Carpet, color, painter, paint.

\footnotetext{
* Öğr. Gör., Selçuk Üniversitesi, Türk El Sanatları Araştırma ve Uygulama Merkezi, Konya.
} aaytac@selcuk.edu.tr 


\section{GİRIŞ}

İnsanoğlunu dış etkilerden koruyabilen, barındıkları mekânda rahat yaşamalarını sağlayabilen ve görsel açıdan zevklerini tatmin edebilen dokuma türleri, mutlaka insanlığın en eski el sanatlarından birisidir.

Geleneksel Türk el sanatlarına bakıldığında dokuma, büyük bir zamana yayılarak devamlılık arz eder (Aytaç 2004: 28). Dokuma, toplumların gelişimlerinin, oluşumlarının, moral ve estetik normlarının, dini ve kültürel inançlarının değerlendirilebildiği teknolojik ve arkeolojik bir araçtır (Özay 2001: 1). Bu araçlara iyi birer örnek olan halı ve kilimler desenleriyle de etnografik birer belge özelliğine sahiptir (Aytaç 2000: 122).

Halının kalıcı özelliği onda tatbik olunan süsleme ve renk yoluyla aksettirilmiştir (Sametoğlu 1996: 115). Dokuma ürünlerin estetiğini yansıtan bu desenler ve renkler, üretildikleri devirlerin konuşan ürünleri, mesaj veren eserleriydi (Aytaç 2004: 45).

Kendi yapamadığını başkalarının yapmasına olanak tanımak günümüz uygar toplumlarının varmak istediği kültür düzeyi ile ilgili bir düşünce ölçüsüdür (Uğurlu 1987: 48). Bozkırın göçebe sanatçısı sanatkârane eğilimlerini, yerleşik uygarlığın sanatçısından değişik yönde yansıtabiliyordu (Diyarbekirli 1969: 142). Avrupalılar ise Türk halısını 1. Haçlı seferi (1096-1099) sırasında tanımışlardır (Güngör 1984: 21).

Avrupa'da XV. yüzyılda, İtalyan, Flaman, Alman vd bazı ressamların tablolarında Selçuklu ve Osmanlı halılarının desenlerini hatırlatan halılar görülür (Yetkin 1964: 06). Ancak henüz XIV. yüzyıl tablolarında da düz dokuma ya da halı olarak dokumaların tablolarda tasvirlendiği de bilinmektedir.

Avrupa prenslerinin zenginlik göstergeleri haline gelmiş ve sahip oldukları halıları ölümsüzleştirmek için zamanın ressamlarına halılarıyla birlikte tablolarını da yaptırmışlardır (Ateş 1994: 18). Yurt içi ve yurt dışı müzelerinde bu tip halı örneklerine rastlanabilir. Washington Tekstil Müzesi'ndeki eşsiz koleksiyonun içerisinde de bu halılar vardır (Delmar 1975: 31).

Tablolarda tasvirlenen halılar bulundukları yere göre ve resimlerde bulunan halıların yörelerine göre gruplandırılmıştır. Tablolardaki renkler ile tasvirlenen halının renkleri arasında da bir bağ olduğu düşünülmektedir. Bu bağın ortaya konması araştırmanın problemi olarak tespit edilmiştir. Renklerde tespit edilmeye çalışılacak olan ilişki genel amacı oluştururken, tabloların tasvirlenen tekstiller bakımından değerlendirilmesi, ressamın halıları tasvirlerken yaptığı değişiklikler, dokumaların yörelerinin belirlenmesi, ait olduğu dönemin saptanması gibi nedenlerde alt amaçları oluşturmuştur.

Araştırmaya sadece $X V$. yüzyıl yüzyılın başlarında resim üretmiş Rönesans ressamlarının bir kısmının sınırlı sayıda tablosu konu olarak seçilmiştir. Örnekler seçilirken üretildikleri dönem ve farklı ressamlardan birer adet tablo ile sınırlandırılması yapılmış olup o dönemin ressamlarının Türk halılarına olan ilgilerinde kullandıkları renklerinde etkileri tespit edilmeye çalışılmıştır. 


\section{Piero della FRANCESCA}

İtalyan ressam ve matematikçidir. Yapıtları, özel bir ilgi duyduğu matematik ve perspektif çalışmalarını yetkin bir resim düzeni içinde yansıtan sanatçı, herhangi bir duygusal ve anlatımcı amaçtan uzak, ama tümüyle gerçeğe uygun bir biçimde gerçekleştirilmiş portre ve tek figürlerinde daha çok hacmin verilmesini amaçlamıştır. İlk olarak A. Lorenzetti'nin renk anlayışından, Gentile de Fabriano'nun berraklığa ve zarif bir biçimlendirmeye dayalı üslubundan etkilendiği görülmektedir. Sanatçı daha sonra Weyden'in etkisine girmiş, Flaman resmi yaşam boyu onu etkilemiştir. Eserleri arasında Rimini S. Francesco Kilisesi'nin Rolikler şapelinin resimleri, Borgo San Sepolcro Halk Sarayı'ndaki 'İsa'nın Göğe Yükselişi' resmi, Urbino yakınındaki S. Bernardino kilisesi için yapmış olduğu 'Brera Altar panosu' sayılabilir.

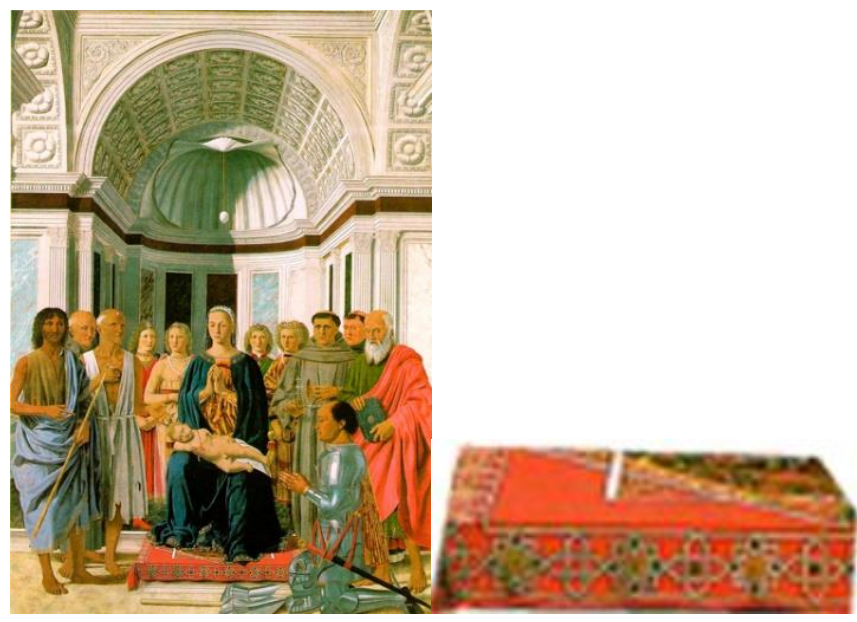

Fotoğraf: 3-4 (Aytaç-Aksoy 1996: 28).

İtalyan ressam Piero della FRANCESCA tarafından 1472-1474 yılları arasında yapılan, 'Meryem ve Çocuğuyla Azizler' isimli, pano üzeri yağlı boya tablo 170x248 cm ebatlarındadır ve Milan Pinacoteca di Brera'da muhafaza edilmektedir.

Kutsal sahnelerle ilgili guruba giren, tahtın altına serili halde resmedilen halının kûfiden gelişmiş sekiz köşeli yıldızlı bordürü ve kırmızı renkli orta kompozisyon alanında madalyon şeklinde iri sekiz köşeli yıldız yanışı kısmen görülmektedir.

Kırmızı renkli orta kompozisyon alanındaki yıldızı ile XIV-XV. yüzyıl Hayvanlı halıları (sekiz köşeli yıldızın uçları girintili olmamakla beraber Crivelli olarak yanlış isimlendirilen halıyı) anımsatan bir yapısı var. İlk Osmanlı halıları üçüncü gurupta ise sekiz köşeli yıldız genellikle sekizgen bir madalyon içerisinde olur. Bu halıda sekizgen bir madalyon olmaksızın yıldız direk olarak orta kompozisyon alanına uygulanmıştır (Aytaç-Aksoy 1996: 29).

Halılar ile tablodaki renklerin bağlantısı: Bu resimde kullanılan halıdaki renkler sıcak ağırlıklıdır. Kırmızı üzerine mavi, yeşil ve sarı renkli motifler yer almaktadır. Halıdaki kırmızı, kompozisyonda yer alan sağ ön kısımdaki yaşlı figürde ve sol arka kısımdaki dördüncü figürde kullanılmıştır. Halıda bulunan yeşil, sarı gibi renklerin aynı zamanda figür ve mekânda da kullanıldığı görülmektedir. Yeşilin tonları kubbenin üzerinde ışı-gölge etkisiyle verilerek resimde bütünlük oluşturmaktadır. 


\section{Hans MEMLING}

Bruges şehrinin politik ve ticari çöküş döneminde Bruges Okulu'na yol göstermiş Flaman ressamdır. Hollanda'da ressam Roger van Weiden ile çalışmış ve 1465'te Bruges'e yerleşmiştir. Eserleri arasında Brugge Memling Müzesi'nde bulunan 'Aziz John Triptiği', Londra Ulusal Galerisi'ndeki 'Bakire Meryem ve Çocuğu', Paris Louvre Müzesi'ndeki 'Jacques Floreins ile Bakire Meryem ve Çocuğu', 'Melek', 'Yaşlı Bir Kadının Portresi' sayılabilir (Sanal 1 2006).

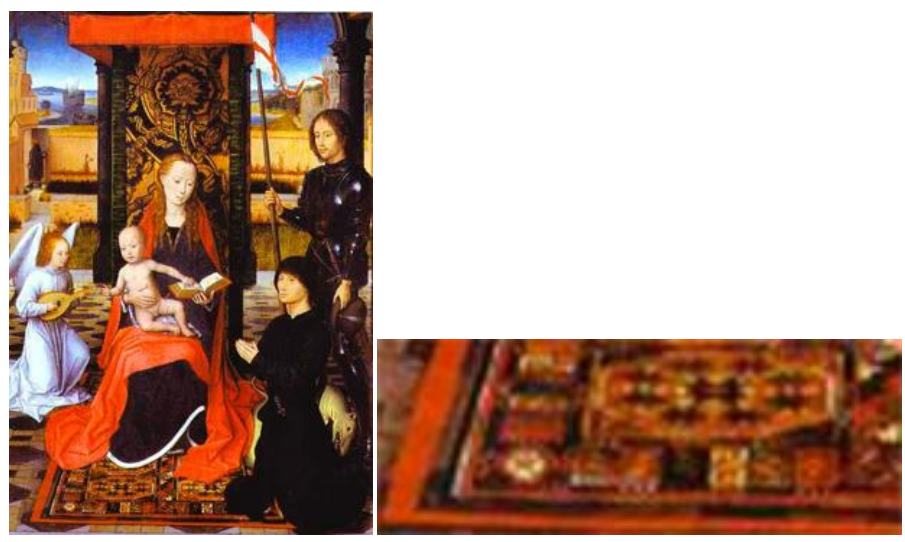

Fotoğraf: 5-6 (Aytaç-Aksoy 1996: 30).

Flaman ressam Hans MEMLING tarafından 1470-1480 yılları arasında yapılan, ‘Bakire ve Çocuk ile Bir Melek, Aziz George ve Bir Bağış Dileyen' isimli tahta üzerine yağlı boya tablo, Londra National Gallery'de muhafaza edilmektedir.

Kutsal sahnelerle ilgili guruba giren ve tahtın altına serili halde resmedilen halının koyu renkli bordüründe sekiz köşeli yıldız ve geometrik yanışlar yer almaktadır. Orta kompozisyon alanı ise bordürün devamı şeklinde dikey istikamette ikiye bölünmüştür ve her iki bölümde de üst üste sekizgenler sıralanmıştır (Aytaç-Aksoy 1996: 31).

İlk Osmanlı halıları beşinci guruba uygun bir kompozisyon şeması görünümü sergilemektedir. Ancak beşinci gurup halılardaki sekizgenlerin kenarları kademeli ve kancalarla (çengellerle) çevrilidir. Bu halıda çengeller görülmemektedir. İlk Osmanlı halılarından beşinci guruba dahil edilebilir. Fakat ressamın kendi sanat anlayışına paralel olarak değişiklikler yaptığına da dikkat edilmelidir.

Halılar ile tablodaki renklerin bağlantısı: Halıda bulunan Türk kırmızısı resmin merkezinde bulunan kadın figürünü çevreleyen kumaşta kullanılarak dikkati figüre çekmektedir. Bu kırmızı rengin dengeleyicisi ise kompozisyonun üst kısmında yer almaktadır. Halıda küçük parçalanmalarda yer alan sarı ve turuncu renkler resmin genelinde daha çok arka planda yer almaktadır. Böylelikle ön ve arka plan ilişkisi renklerle de sağlanmıştır.

\section{Andrea del VERROCCHIO}

Floransa'lı heykeltıraş ve ressamdır. Çıraklık dönemini Erken Rönesans'ın büyük İtalyan heykeltıraşı Donatello'nun yanında yaptığı düşünülmekteyse de ilk heykel çalışmalarındaki stilistik eğilimi Donatello'dan ziyade Antonio Rossellino'ya benzediği için bu bilgi şüphe uyandırmaktadır. İlk resim çalışmaları muhtemelen 1460'ların ortalarından itibaren başlamıştır. Verrocchio, Floransa'lı sanatçı Alesso Baldovinetti'nin öğrencisi olduğunu söylemiştir. Fakat onun Sandro Boticceli ile birlikte Floransa yakınlarında bir kent olan Prato'da, erken Rönesans 
ustası Fra Filippo Lippi'nin altında çalıştığı düşünülmektedir. Eserleri arasında Paris Louvre Müzesi'ndeki 'İki Uçan Melek', Amsterdam Rijks Müzesi'ndeki 'Şamdan', Floransa Uffizi Galeri'deki 'İsa'nın Vaftizi' sayılabilir (Sanal 2 2006).

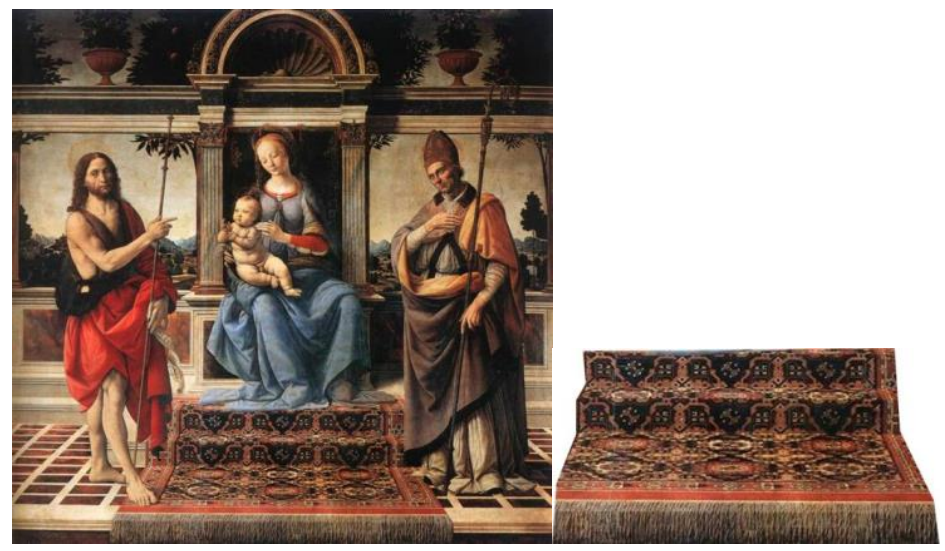

Fotoğraf: 7-8 (Aytaç-Aksoy 1996: 34).

İtalyan ressam Andrea del VERROCCHIO tarafından 1475-1483 yılları arasında yapıldığı tahmin edilen ve Pistoia Duomo'da bulunan 'Vaftizci Yahya ile Madonna ve Donatus' adlı tablo tahta üzerine yapılmış olup, 191x189 cm ölçülerindedir.

Kutsal sahnelerle ilgili guruba giren ve tahtın altına serili halde resmedilen halının bordürlerinde çiçekli kûfiler yer alırken, koyu renkli zeminde geometrik halde bitkisel yanışlar ve dikdörtgen raport bir şema görülmektedir (Aytaç-Aksoy 1996: 35). İlk Osmanlı halıları birinci guruba dahildir.

Halılar ile tablodaki renklerin bağlantısı: Halıda yer alan koyu lekeler, karolarda, arka plandaki yapılarda, bitkiler de ve figürlerin genelinde kullanılmıştır. Halıdaki turuncu ve kırmızılar ise sadece figürlerde yer almıştır. Kırmızı renk sol figürde ağırlıkta, ortadaki figürde daha az görülmektedir. Turuncu renk ise sadece sağ figürde yer almaktadır. Ayrıca halıda bulunan açık sarı gibi tonlar figürlerin ten renklerinde kullanılmıştır.

\section{Domenico GHIRLANDAIO}

Erken dönem Floransa sanatında özellikle Fresk alanında etkinlik göstermiş İtalyan ressamdır. Anlayışı Masaccio ile Fra Fillipo Lippi'nin üsluplarının daha basit bir kavrayışla ele alınmasıyla biçimlenmiştir. Fresk dışında tempera çalışmış, hiç yağlıboya yapmamıştır. Eserleri arasında Ognissanti Kilisesi'ndeki 'Aziz Hieronymus ve Son Akşam Yemeği', Floransa S. Maria Novella Kilisesi'nde 'Meryem ve Vaftizci Yahya'nın Yaşamından Sahneler' çalışması, Louvre Müzesi'ndeki 'Yaşlı Adam ve Torunu' sayılabilir. 


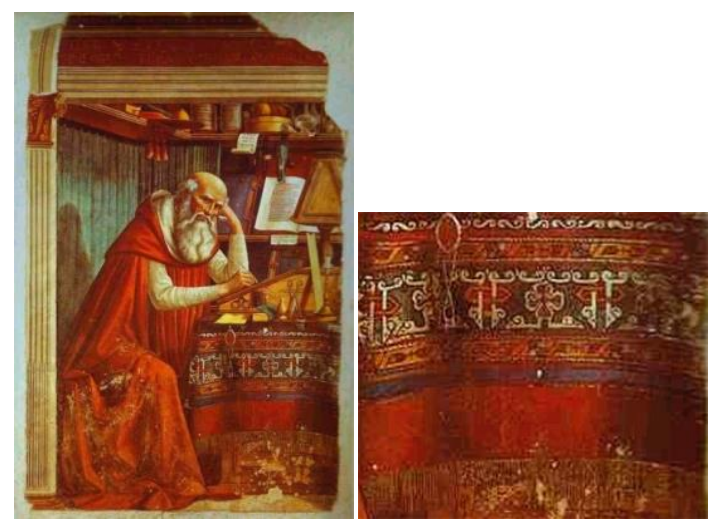

Fotoğraf: 9-10 (Aytaç-Aksoy 1996:42).

İtalyan ressam Domenico GHIRLANDAIO tarafından 1480 yılında yapılan 'Aziz Jerome' isimli fresk Floransa Ogni Santi Kilisesi'nde bulunmaktadır.

Masa üzerinde serili halde olan guruba dahil olan halının kilim örgüsü kısmı alışılagelmiş ölçülerden oldukça uzun resmedilmiştir. Dış küçük ve iç birinci küçük bordürde suyolu şeklinde çengeller sıralanmaktadır. Büyük bordürde ise çiçekli kûfi tarzı bir bordür yer almaktadır. İç ikinci küçük bordürde ise beyaz renkli "S" şeklinde çengeller bulunmaktadır. Orta kompozisyon alanında da çok net görülmemekle beraber, küçük sekizgen madalyonu andıran bir şema yer almaktadır (Aytaç-Aksoy 1996: 43).

$\mathrm{Bu}$ halının bordürlerinin benzeri olan bir halı, İsviçre'de Wher koleksiyonunda bulunmaktadır (Yetkin 1991: 40). Çiçekli kûfiden gelişen büyük bordürü, çengelleri ve orta kompozisyon alanı şeması ile İlk Osmanlı halıları birinci guruba dahil olan Bergama civarına ait bir Batı Anadolu halısı tasviridir.

Halılar ile tablodaki renklerin bağlantısı: Halıda dikkati çeken kırmızı tonları resmin geneline hâkimdir. Figürün üzerinde bulunan giysi tamamen bu kırmızının tonlarından oluşmaktadır. Aynı zamanda mekânın üst kısmı olan duvarda ve objelerde bu rengin kullanılmasıyla bütünlük sağlanmıştır. Halıda yer alan diğer mor ve yeşil renkler resmin orta kısmında yer alan objelerde de kullanılmıştır.

\section{Vincenzo FOPPA}

Erken Rönesans dönemi İtalyan ressamıdır. 1456'ya doğru Pavia'ya yerleşmiş ve Leonardo da Vinci'nin gelişine kadar Lombard Resim okulunun başı olmuştur. Eserleri arasında Saint Petersburg Hermitaj Müzesi'nde bulunan 'Aziz Stephen', Minnesota'da Minneapolis Sanat Enstitüsü'ndeki 'Aziz Paul', 'Aziz Sirus', Londra Ulusal Galeri'deki 'Krallara Tapınma', Milan'da Poldi Pezzoli Müzesi'ndeki 'Bakire Meryem ve Çocuk', 'Giovanni Francesco Brivio'nun Portresi' sayılabilir (Sanal 3 2006). 


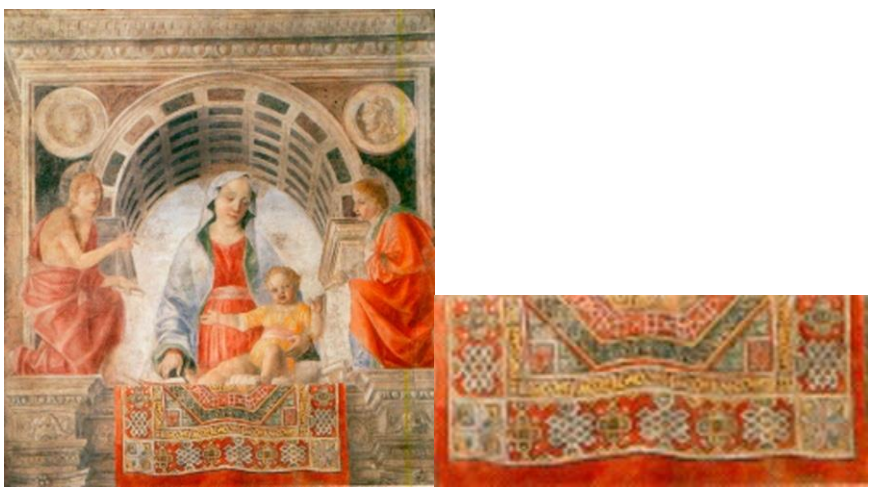

Fotoğraf: 11-12 (Aytaç;Aksoy,1996: 46).

İtalyan ressam Vincenzo FOPPA tarafından 1485 tarihinde yapılan 'Madonna Çocuğuyla, Aziz Giovanni Battista ve Evangelist Giovanni'nin Arasında' isimli tablo $173 \times 192 \mathrm{~cm}$ ölçülerindedir.

Kutsal sahnelerle ilgili olarak balkondan sarkıtılmış halde bulunan halı tasvirleri gurubuna dahildir. Kırmızı renkli büyük bordüründe geometrik yanışlar vardır. İç taraftaki küçük bordürde ise çengel yanışları sıralanmıştır. Orta kompozisyon alanı ise karelere bölünmüş olup, yeşil renkli sekizgen iri madalyon yerleştirilmiştir. Sekizgenin boşluklarına ise üçgenimsi yapıda ejderha figürleri yer alır (Aytaç-Aksoy: 1996: 47). İlk Osmanlı halıları üçüncü guruba dahil Bergama halısı tasviridir.

Halılar ile tablodaki renklerin bağlantısı: Resmin ön orta kısmında bulunan Halıda kırmızı renk ağırlıktadır. Sarı, mavi ve yeşil tonları da halıda küçük parçalanmalarla yer almıştır. Kompozisyonda ortasında bulunan 3 figürde halıda bulunan kırmızının değişik tonları görülmektedir. Sarının tonları ise ağırlıklı olarak bebek figüründe vardır. Açık mavi renk, gökyüzü ve kompozisyonun ortasındaki figürde baskın olarak kullanılmıştır. Yapılarda ise halıdaki yeşil tonları mevcuttur.

\section{Cima da CONEGLIANO}

Venedik Okulu'na önemli katkıda bulunmuş İtalyan ressamdır. Treviso Conegliano'da doğmuştur. Muhtemelen Bartolomeo Montagna'nın öğrencisi olmuştur. Daha sonra Giovanni Bellini'den çok etkilenmiş ve onun en güçlü haleflerinden biri olmuş, bununla birlikte Bellini'nin başarısına ulaşamamıştır. Başlangıçta figürleri inceliksiz olduğu halde derece derece sertliğini yitirmiş ve resimleri hala bir saygınlık hissi sunarken, zarafeti ilerlemiştir. Eserleri arasında Cambridge Üniversitesi Fitzwilliam Müzesi'nde bulunan 'Vaftizci Yahya ve Aziz Liberius arasında Tahta Çıkmış Aziz Lanfranc', Rusya Hermitaj Müzesi'ndeki 'Göğe Yükseliş', Amerika Ulusal Sanat Galerisi'ndeki 'Aziz Jerome ve Vaftizci Yahya ile Madonna ve Çocuğu', sayılabilir (Sanal 4 2006). 


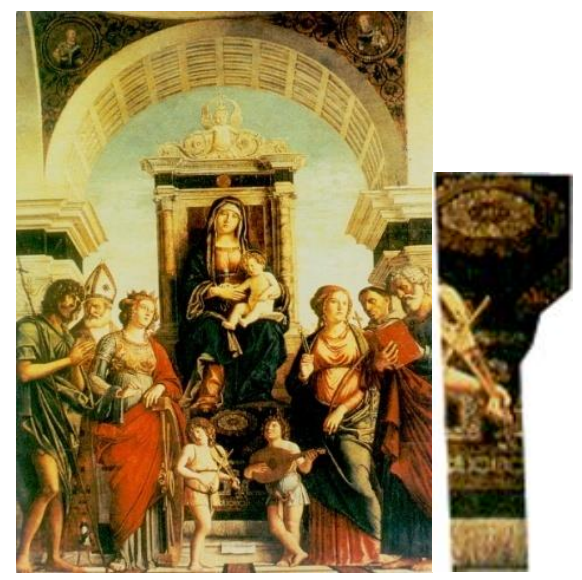

Fotoğraf: 13-14 (Aytaç-Aksoy 1996: 48).

İtalyan ressam Cima da CONEGLIANO tarafından 1492-1493 tarihlerinde yapılmış olan tablo ‘Tahta Çıkmış Meryem ve Çocuğuyla Altı Aziz' ismini taşımaktadır.

Kutsal sahnelerle ilgili halı tasvirleri gurubuna dahildir. Anahtar delikli şemaya sahip orta kompozisyon alanında ortada bir madalyon görülmektedir (Aytaç-Aksoy 1996: 49). İlk Osmanlı halıları altıncı guruba dahil Bergama karakteri taşıyan bir halı tasviridir.

Halılar ile tablodaki renklerin bağlantısı: Resmin küçük bir alanında yer alan halıda soğuk renkler hâkim kılınmıştır. Halıda ağırlıklı olan yeşil renk kompozisyonun ortasında yer alan kadın figüründe baskın olarak kullanılırken, diğer figürlerde de tonları görülmektedir. Yine aynı renk kolonlarda ve tahtın üst kısmında bulunmaktadır. Halıda yer alan açık değerdeki renkler ise resmin genelinde mevcuttur.

\section{SONUÇ ve ÖNERILER}

Tablolarda resmedilen halıların bire bir olarak aynen aktarılmadığı, ancak aslına çok yakın şekilde tasvirlendiği de görülmekle beraber, sanatçının bir tasarımcı edasıyla tasvirlediği halılarda küçük ya da büyük değişiklikler yaptığı da gözlemlenmiştir.

Araştırma kapsamında incelenen altı tablonun her birinin ilgili yüzyıllarda üretilmiş olmasına ve farklı ressamların çalışmalarından ibaret olmasına dikkat edilmiştir.

Tablolarda tasvirlenen dokumaların renklerinin tablolardaki diğer objeler deki renklerle de ilişkili olduğu bu çalışma ile tespit edilmiştir. Ressamların kullandıkları renkleri rastgele seçmedikleri hatta tasvirlenen halılarda kullandıkları renklerle tablodaki diğer objelerde kullanılan renklerle ilişki kurarak, renk dağılımını ince bir hesapla ortaya koydukları anlaşılmıştır.

\section{SUMMARY}

Handcrafts were developed from needs. Textiles are important in Turkish handicrafts. The history of weaving has a long history in history. Turks have produced important works in this area for centuries.

In Europe, XIV. an interest in Turkish life emerges from the beginning of the century. Having Turkish carpets is an important privilege. Everyone tried to own a Turkish carpet.

In European painters, they start to depict Turkish carpets in their paintings. European 
princes have made their paintings with famous Turkish painters of the period.

Many Turkish carvings from those periods are now exhibited in the museums of European countries.

It is thought that there may be a connection between the colors in the paintings produced by foreign painters and the colors of the carpets. It is also seen in the painting of a carpeted carpet used in a table or an object.

Investigate XV. Some of the century's paintings were included. talian painter Piero della FRANCESCA with Saint Mary and the Child, Flemish painter Hans MEMLING's Virgin and Child with an Angel, Saint George and a Donation Wishing Andrea del VERROCCHIO Baptist Yahya with Madonna and Donatus, Domenico GHIRLANDAIO's Saint Jerome, Madonna Child of Vincenzo FOPPA, St. Giovanni Battista and Evangelist Giovanni, and Cima da CONEGLIANO's Six Outrageous Tables with Mother and Child.

The carpets depicted in the tables are classified according to their location. It has been tried to determine which group is included with the local pattern character. In addition, the relation between colors and the colors of the carpet was tried to be revealed.

It is understood that the colors used on the tables are not chosen randomly by painters. It has been found that painters have a relationship between the colors in the tables and the colors in the carpet depictions. 


\section{KAYNAKÇA}

ATEŞ, Mehmet (1994) Türk Halıları, Nevşehir.

AYTAÇ, Ahmet, (2000) "Ilgın Çiğil Kilimleri", S. Ü. M. E. F. III. Ulusal Türk El Dokumalarna Yaklaşım ve Sorunları Sempozyumu Bildirileri, Konya, s.122-130.

AYTAÇ, Ahmet (2004) "Konya Yöresi Halı ve Kilim Dokumalarında Yıldız Yanışı” Tarih Dergisi İstanbul, 210, 28-31.

AYTAÇ, Ahmet; AKSOY, Aslı (2006) Yabancı Ressamların Tablolarında Tasvirlenen (15-20 yy.) Türk Halılar Konya.

DELMAR, L., Roberts (1975) “Washington Tekstil Müzesi'nde Türk Halıları" Türkiyemiz Dergisi İstanbul 16, 28-32.

DIYARBEKIRLİ, Nejat, (1969) “Türk Sanatının Kaynaklarına Doğru” Türk Sanat Tarihi Araştırma ve İncelemeleri Türk Sanat Tarihi Enstitüsü Özel Sayısı İstanbul, 112-177.

GÜNGÖR, Hulusi, (1984) Türk Halıları İstanbul.

ÖZAY, Suhandan, (2001) Dünden Bugüne Dokuma Resim Sanatı Ankara Kültür Bakanlı̆ğ Yayın No: 2599/322.

UĞURLU, Aydın, (1987) “Orta Çağ Anadolu Dokuma Sanatı” İlgi Dergisi İstanbul, 48.

YETKINN, Şerare, (1991) Türk Halı Sanatı İş Bankası Yayınları Ankara.

\section{İnternet kaynakları}

www. artcyclopedia.com/artists/ huguet_jaume.html.01.02.2006.

Sanal 12006

www.kfki.hu/ arthp/bio/m/memling/biograph.html,users.pandora.be/bernard/Artpics/Memli ng.htm.01.02.2006.

Sanal 22006

www.kfki.hu/ arthp/bio/v/verocchi/biograph.html,www.artcyclopedia.com/artists/verrocchio andrea del.html01.02.2006.

Sanal 32006 www.artcyclopedia.com/artists/foppa vincenzo.html. (01.02.2006).

Sanal 42006 www.newadvent.org/cathen/a.htm,www.artcyclopedia.com/artists/conegliano giambattista_cima_da.html. (01.02.2006). 